\title{
SYNTHESIS OF GRAFT COPOLYMER FROM ETHYL METHACRYLATE ONTO DELIGNIFIED GREWIA OPTIVA FIBER
}

\author{
Vivek Nandani
}

Kinnari Trivedi

\begin{abstract}
:
Ethyl methacrylate was grafted onto delignified Grewia optiva fiber using ascorbic acid/H2O2 as redox initiators in an aqueous medium. The reaction variables including concentration of ascorbic acid, $\mathrm{H}_{2} \mathrm{O} 2$, monomer and amount of backbone as well as time and temperature have been varied for establishing grafting. The influence of these reaction conditions on the grafting yield has been discussed. The overall activation energy of grafting has been calculated. The FT-IR spectroscopy, Thermal Gravimetric Analysis (TGA) and Scanning Electron Microscopic (SEM) techniques have been used for the characterization of graft copolymer.
\end{abstract}

Key Words: Ascorbic Acid, optimized reaction conditions, graft co-polymer, FTIR, TGA.

\section{Introduction}

Natural biomasses such as natural fibers are utilized by humans for household or other conventional applications $[1,2,3]$ during the past few decades, natural polymers have found various applications in different fields such as building materials, sports equipment, automobiles, electrolytes, energy storage, aerospace, and as adsorbent for toxic metal ion from different resources [4]. Graft copolymerization of vinyl monomers onto natural and synthetic polymers has the advantage of incorporation of additional properties of the monomer. In the present study, efforts have been made to modify the surface of deilgnified Grewia optiva fiber through graft copolymerization method with ethyl methacrylate vinyl monomer using ascorbic acid (AA)/ $\mathrm{H}_{2} \mathrm{O} 2$ redox initiator. Grewia optiva fiber had a composition of approximately 58-62\% cellulose, 22-24\% hemicelluloses, and 14-16\% lignin.

\section{Experimental, Materials and Methods}

The monomer Ethyl methacrylate (EMA) were received from S.D. Fine, India and used as received. Acetone of 99\% purity supplied by Chiti Chem. Pvt. Ltd., India was used for removal of 
homopolymer. AA and hydrogen peroxide $\left(\mathrm{H}_{2} \mathrm{O}_{2}\right)$ were supplied by Samir Tech, Chem. Baroda, Gujarat of analytical reagent grade was used as received used as initiator. Weighing of the samples was done on AutoCAL Digital ATA-320 electronic balance.

\section{Graft copolymerization}

A $250 \mathrm{~mL}$ three necked flask equipped with mechanical stirrer, a reflux condenser and a gas inlet system were immersed in a constant temperature bath for grafting reactions. In a typical reaction, varying amount $(0.50-3.50 \mathrm{~g})$ of the delignified Grewia optiva fiber was dissolved in distilled water $(110 \mathrm{~mL})$ with constant stirring and bubbling a slow stream of nitrogen for $1 \mathrm{~h}$ at the $40^{0} \mathrm{C}$ temperature. The EMA $(0.051-0.405 \mathrm{M})$ was then added

to the charge. After $5 \mathrm{~min}$., the freshly prepared $10 \mathrm{~mL}$ solution of AA $\left(15 \times 10^{-3}\right.$ -

$\left.50 \times 10^{-3} \mathrm{~mol} / \mathrm{L}\right)$ in distilled water was added.

$\mathrm{H}_{2} \mathrm{O} 2\left(.097-8.09 \mathrm{~mol} / \mathrm{L} \times 10^{-1}\right)$ and this time was taken as zero time for reaction. The grafting reactions were carried out for different time intervals $(0.5-10 \mathrm{~h})$. During the course of the reaction, a slow stream of nitrogen was continuously passed to remove the dissolved oxygen. After completion of the reaction, the contents of the flask were poured immediately into excess of methanol to precipitate out the polymer. The crude copolymer product was then filtered, repeatedly washed with $95 \%$ methanol and finally with pure methanol. The crude sample thus obtained was dried under vacuum at

$40^{0} \mathrm{C}$. The homopolymer was removed from

the crude graft copolymer by exhaustive soxhlet extraction with acetone for 48 hours. Percent graft yield (\% PG), percent graft efficiency (\% PE), were calculated by following methods $[5]$.

$$
\% \text { Grafting }(\mathrm{pg})=\mathrm{Wg}-\mathrm{WW} \times 100
$$

$\%$ Efficiency (pe) $=\mathrm{Wg}-\mathrm{WWm} \times 100$

where $\mathrm{W}, \mathrm{Wg}$ and $\mathrm{Wm}$ are the weights of delignified fiber, grafted fiber and monomer.

\section{IR SPECTRA}

The IR spectra of delignified Grewia optiva fiber delignified Grewia optiva fiber- gPEMA and PEMA were taken in Perkin Elmer BX FT-IR Fourier Transform Infrared Spectrophotometer.

\section{THERMOGRAVIMETRIC ANALYSIS (TGA)}

delignified Grewia optiva fiber and its graft copolymer delignified Grewia optiva fiber - gPEMA and PEMA under inert atmosphere at a scan rate of $10^{0} \mathrm{C} / \mathrm{min}$. 


\section{RESULT AND DISCUSSION Determination of optimum reaction conditions}

The reaction variables including concentration of initiators (ASC \& $\mathrm{H} 2 \mathrm{O} 2$ ), monomer (EMA), substrate concentration as well as time and temperature have been varied for establishing the optimized reaction conditions for grafting.

\section{(a) Effect of Backbone Concentration}

Graph-1 show the dependence of percentage grafting (\%PG) as well as percentage grafting efficiency $(\% \mathrm{PE})$ on the backbone concentration in the case of EMA. It is observed from this graph that with increasing delignified Grewia optiva fiber concentration, the values of \% $\mathrm{PG}$ and $\% \mathrm{PE}$ are found to be increased in the beginning up to optimum concentration i.e. delignified Grewia optiva fiber $=2.0 \mathrm{~g}$. Beyond which they are decreased with future increase in the amount of backbone.

Thus, the observed initial increase in $\% \mathrm{PG}$ up to $2.0 \mathrm{~g}$, is due to the fact that the reactive sites increase with increase in the concentration of delignified Grewia optiva fiber and after the optimum concentration, the observed decrease in $\% \mathrm{PG}$ is due to the destruction of radical activity backbone concentration soon after it is formed because of termination between backbone-backbone and backbone-primary radicals. Similar result was seen in [6].

\section{Graph-1}

Grafting yields for grafting of EMA onto delignified Grewia optiva fiber at various backbone concentrations

\section{Effect of Substrate}

120

100 

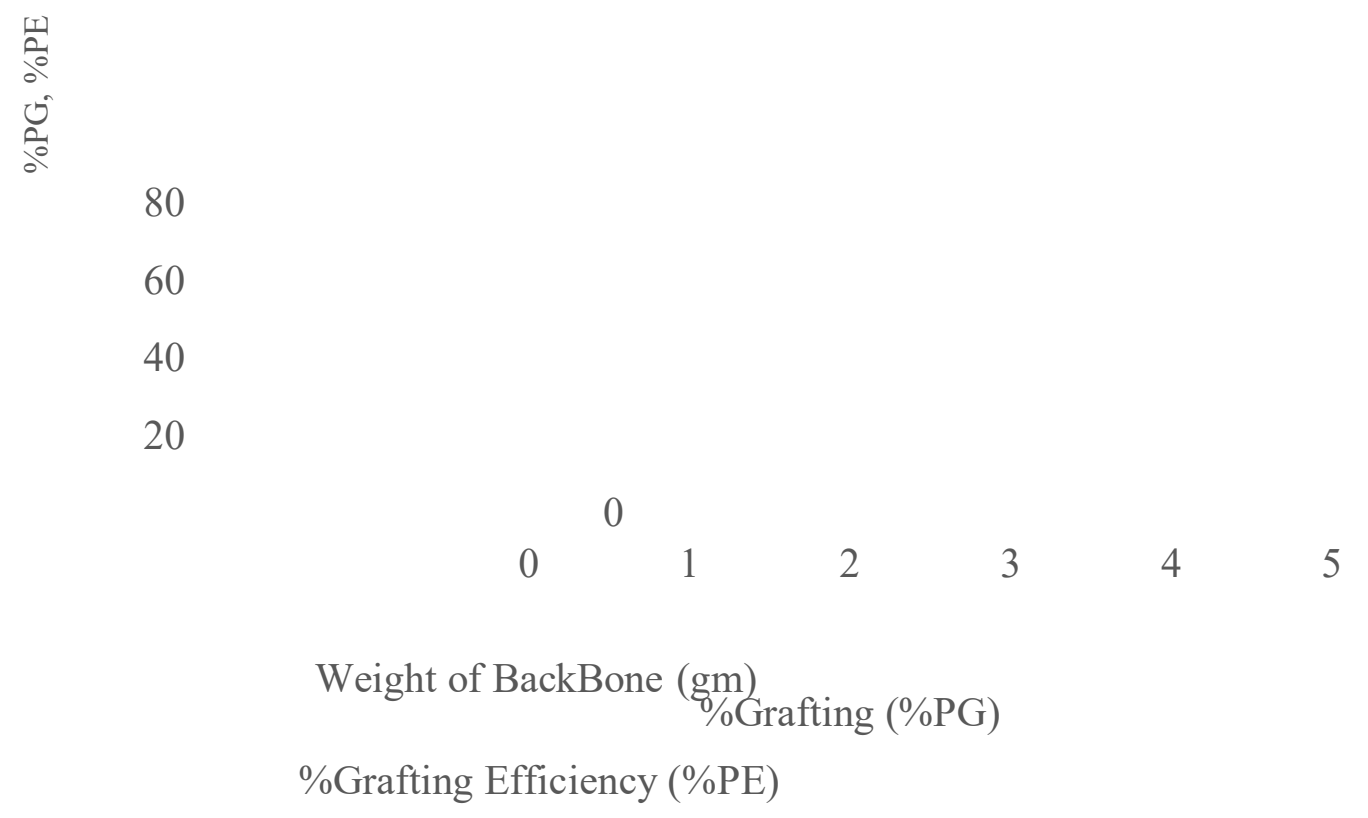

increasing monomer (EMA) concentration could be associated with the grater availability of monomer molecules in the vicinity of delignified Grewia optiva fiber in particular and in the reaction medium in general [117-119]. It may also be noted that once the graft copolymer radicals are formed, the excess monomer will shield the graft copolymer, which may inhibit the rate of graft copolymerization. In addition to this the excess monomer will be available for initiator radicals to initiate the homopolymerization reaction and thereby decrease the grafting efficiency. Similar results were seen in $[7,8]$.

\section{Graph-2}

Grafting yields for grafting of EMA onto delignified Grewia optiva fiber at various monomer concentrations.

\section{Effect of Monomer}

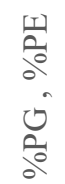

(b) Effect of Monomer Concentration

The value of $\% \mathrm{PG}$ increases from

$0.051-0.405 \mathrm{M}$ and reaches a maximum value of $\% \mathrm{PG}=98.65$. Beyond $[\mathrm{EMA}]=3.20 \mathrm{~mL}$ the 
value of $\% \mathrm{G}$ is found to be decreased with future increase in the concentration. On the other hand, $\% \mathrm{PE}$ decreases continuously

in the whole range of concentration of EMA

$\begin{array}{llllll}0 & 2 & 4 & 6 & 8\end{array}$

\section{Amount of Monomer (ml)}

\%Grafting (\%PG)

$\%$ Grafting Efficiency (\%PE)

studied. The enhancement of grafting by

\section{(c) Effect of $\mathrm{H}_{2} \mathrm{O}_{2}$ concentration}

The influence of the $\mathrm{H}_{2} \mathrm{O}_{2}$ concentration on the grafting onto delignified Grewia optiva fiber is shown in Graph 3. The $\% \mathrm{PG}$ and $\% \mathrm{PE}$ decreased progressively with rising [H2O2] until it levels off at $0.35 \mathrm{ml} \mathrm{H} 2 \mathrm{O}_{2}$. At high [ $\left.\mathrm{H}_{2} \mathrm{O}_{2}\right]$ there are more radicals produced which may combine to promote termination of radical on the cellulose backbone and the termination of the polymerization reactions. The results obtained in this study confirm that a high $\left[\mathrm{H}_{2} \mathrm{O}_{2}\right]$ will not increase the graft yields even though there may be an increase in total polymers produced.

\section{Graph-3}

Grafting yields for grafting of EMA onto delignified Grewia optiva fiber at various monomer concentrations. 


\section{(d) Effect of Ascorbic Acid Concentration}

\section{[Activator]}

The influence of ascorbic acid (AA) concentration on grafting yields of EMA and onto delignified Grewia optiva fiber is shown in Graph 4. It is evident from this graph that with increasing ascorbic acid concentration the value of $\% \mathrm{PG}$ increases and reaches a maximum value of $121.99 \%$ at $[\mathrm{AA}]=20 \times 10^{-3} \mathrm{~mol} / \mathrm{L}$ for EMA. With further increase in the concentration of activator (ascorbic acid), the value of $\% \mathrm{G}$ is found to be decreased.

Graph 4 indicate the influence of the activator (ascorbic acid) concentration on the values of $\% \mathrm{PG}$ and $\% \mathrm{PE}$. The increase in values of $\% \mathrm{PG}$, and \% $\mathrm{PE}$ with the ascorbic acid concentration range, is attributed to the

fact that in the presence of ascorbic acid,

Effect of Initiator Conc.

and

4

$\mathrm{SO}^{--\bullet}$ radicals generated in the

80

60

40

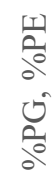

20

0
0
0.1
0.2
0.3
0.4
0.5

Hydrogenperoxide Con.

\%Grafting $(\% \mathrm{PG}) \quad$ \%Grafting Efficiency $(\% \mathrm{PE})$ 
system, may attack the delignified Grewia

optiva fiber resulting in more active sites on delignified Grewia optiva fiber followed by the addition of monomer (EMA). Beyond the optimum concentration of the activator the observed decrease in percentage grafting and percentage grafting efficiency is due to the increased formation of ascorbaet radicals

homopolymerization. Similar result is reported in [9].

) which are mainly responsible for

\section{Graph- 4}

Grafting yields for grafting of EMA onto delignified Grewia optiva fiber at various Ascobic Acid concentrations.

\section{Ascorbic Acid Effect}

of temperature on : (a) the swelling of delignified Grewia optiva fiber (b) the solubility of monomer (EMA) molecules, (c) the enhanced diffusion of monomer molecules (EMA) from aqueous phase to the delignified Grewia optiva fiber backbone, (d) the increase in the mobility

of the monomer (EMA) molecules and their collision with delignified Grewia optiva fiber macroradicals, and (e) the rates 


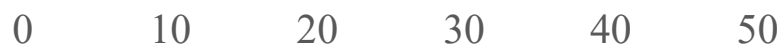

\%Grafting $(\% \mathrm{AAG})$

$\%$ Grafting Efficiency $(\% \mathrm{PE})$

of initiation and propagation of grafting. The observed decrease in $\% \mathrm{PG}$ beyond $45^{0} \mathrm{C}$ can be ascribed to the fact that after attaining respective optimum temperature, graft copolymerization occurs with poor selectivity. In addition, various hydrogen abstraction and chain transfer reactions also might be accelerated at higher temperature leading to decrease in percentage of grafting. Similar results were in $[10,11]$.

\section{(e) Effect of Reaction Temperature}

The results in Graph-5 indicate that initially with increasing temperature, \% $\mathrm{PG}$ increases and reaches a maximum value $(\% \mathrm{PG}=133.16)$ at temperature $45^{0} \mathrm{C}$. Beyond the optimum value of temperature,

$\% \mathrm{PG}$ decreases with further increase in temperature. Thus, the observed increase in percentage grafting with temperature can be interpreted in terms of favourable influence

\section{Graph-5}

Grafting yields for grafting of EMA onto delignified Grewia optiva fiber at various temperatures.

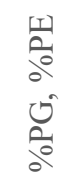

Effect of Temperature 


\section{Graph- 6}

Grafting yields for grafting of EMA onto delignified Grewia optiva fiber at various time intervals.

\section{0}

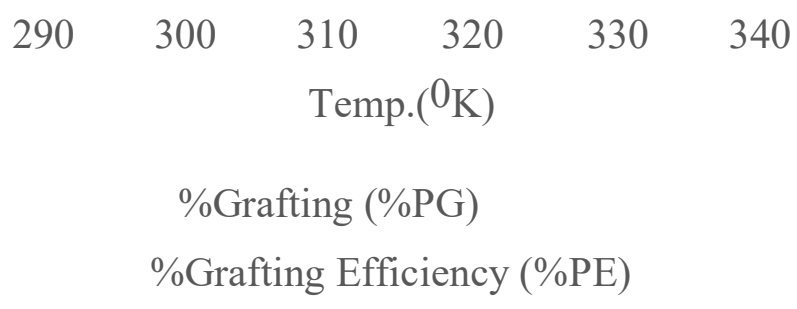

\section{(f) Effect of Reaction Time}

It is evident from the figure that the percentage grafting increases upto a maximum of $135.51 \%$ within $1.5 \mathrm{~h}$. The initial increase in $\% \mathrm{PG}$ is due to the increase in number of grafting sites on the delignified Grewia optiva fiber backbone as reaction progresses. But beyond the optimum time, i.e. 2.5 $\mathrm{h}$, the value of $\% \mathrm{PG}$ decreases which is due to the depletion in monomer and initiator concentrations as well as shortage of the available grafting sites. The initial increase in the value of $\% \mathrm{PE}$, as observed in

Graph 6 is attributed to the formation of more and more delignified Grewia optiva fiber grafted radicals, during the process of grafting reaction and beyond the optimum time the observed decrease in \% $\mathrm{PE}$ is due to the homopolymer (PEMA) formation. Similar result was seen in $[12,13]$. 
0

$$
\begin{array}{cccr}
0 & 5 & 10 & 15 \\
& \text { Time (hrs) } & \\
\text { \%Grafting (\%PG) } & \text { \%Grafting Efficiency (\%PE) }
\end{array}
$$

Thus, on the basis of this discussion, the optimized reaction conditions obtained for the graft copolymerization of EMA are shown in Table 1.

\section{TABLE 1}

\begin{tabular}{|l|l|}
\hline $\begin{array}{l}\text { delignified Grewia } \\
\text { optiva fiber }\end{array}$ & $2.0 \mathrm{~g}$ (dry basis) \\
\hline$\left[\mathrm{H}_{2} \mathrm{O}_{2}\right]$ & $0.05 \mathrm{~mL}$ \\
\hline$[\mathrm{AA}]$ & $20 \times 10^{-3} \mathrm{M} ;$ \\
\hline$[$ EMA $]$ & $3.20 \mathrm{~mL}$ \\
\hline Time & $2.5 \mathrm{~h}$ \\
\hline Temperature & $40^{0} \mathrm{C}$ \\
\hline Volume of Water & $146.6 \mathrm{~mL}$ \\
\hline Total Volume & $150 \mathrm{~mL}$ \\
\hline
\end{tabular}

\section{Optimized Reaction Conditions}

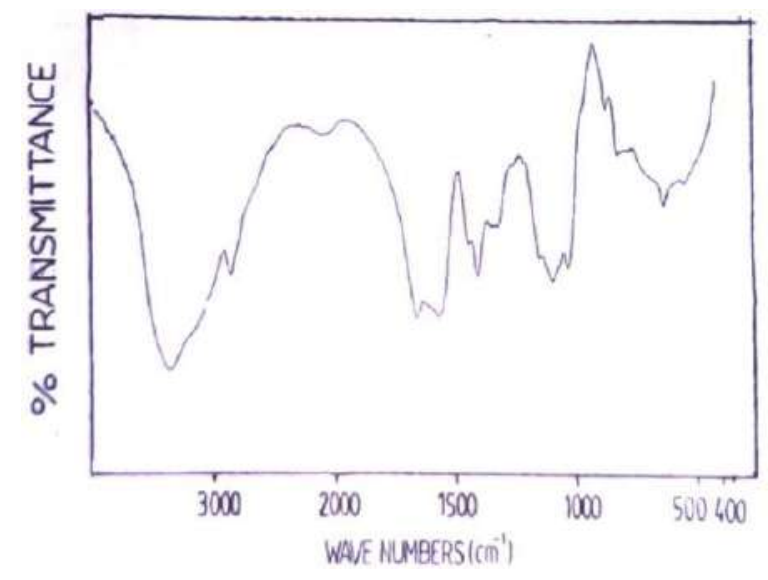

Fig.1: IR spectra of delignified Grewia optiva fiber sample. 
Fig.1 shows the IR spectrum of delignified Grewia optiva fiber. The peaks are observed at $1633.27 \mathrm{~cm}^{-1}$ (due to H-O-H bending of absorbed water, $2922.31 \mathrm{~cm}^{-1}$ (for $\mathrm{C}-\mathrm{H}$ stretching vibration of aliphatic methylene groups), and $3431.39 \mathrm{~cm}^{-1}$ (due to bonded $\mathrm{OH}$ group) .

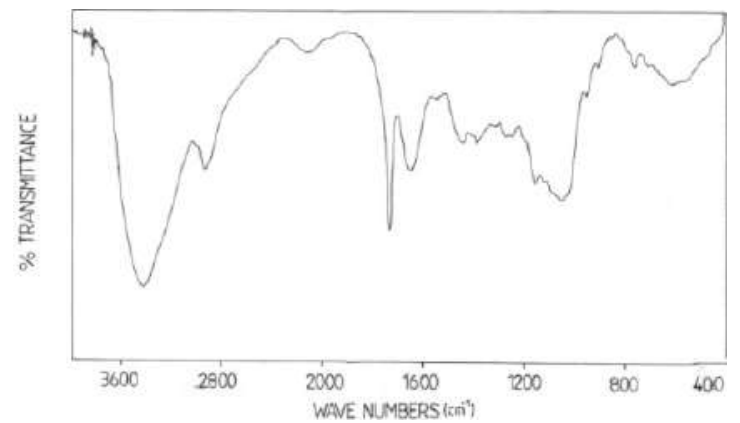

\section{Fig. 2: IR spectra of delignified Grewia optiva fiber -g-PEMA sample.}

The IR spectrum of the copolymer delignified Grewia optiva fiber -g-PEMA (Fig.2) showed absorption bands of delignified Grewia optiva fiber as well as an additional peak at $1732.24 \mathrm{~cm}^{-1}$ due to the carbonyl group $(>\mathrm{C}=\mathrm{O})$ of EMA. This confirms the grafting of EMA onto delignified Grewia optiva fiber. Moreover, this graft copolymer (namely delignified Grewia optiva fiber -g-PEMA) was hydrolyzed in order to isolate the grafted chains i.e. PEMA. The infrared spectrum of PEMA (Fig.3) shows the presence of $-\mathrm{C}=\mathrm{O}$ stretching at about $\sim 1730 \mathrm{~cm}^{-1}$. This may be attributed to the fact that the hydrolysis of the graft copolymer gives back; the grafted chain PEMA. Thus, the results of Figs. 2 and 3 provide a substantial evidence of grafting of EMA onto delignified Grewia optiva fiber.

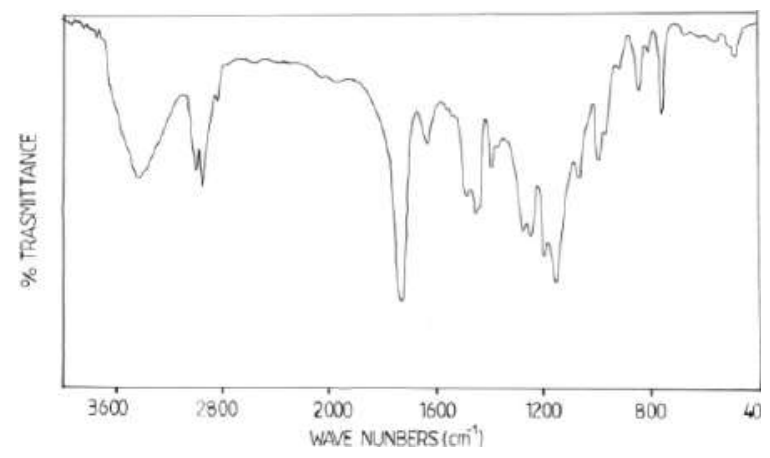


Towards Excellence: An Indexed, Refereed \& Peer Reviewed Journal of Higher Education / Vivek Nandani \& Kinnari Trivedi / Page 350-365

March, 2021. VOL.13. ISSUE NO. 1 
Fig. 3: IR spectra of Polyethyl methacrylate (PEMA) sample.

\section{SCANNING ELECTRON MICROSCOPY (SEM)}

The scanning electron micrograph of delignified Grewia optiva fiber (Plate 1) shows the lump surface with uneven arrangement of ungrafted material.

The surface topology of delignified Grewia optiva fiber -g-PEMA (\%PG = 126.25) can be seen in Plate 2. Upon comparing the morphology of the grafted samples (Plates 2. with ungrafted material (Plate 1) it is clearly evident that the grafted chains have drastically changed the topology delignified Grewia optiva fiber sample. Depending upon the individual nature of the monomer used for grafting onto delignified Grewia optiva fiber. In both this case, additional surface deposits and even arrange is clearly seen from the plate 2.

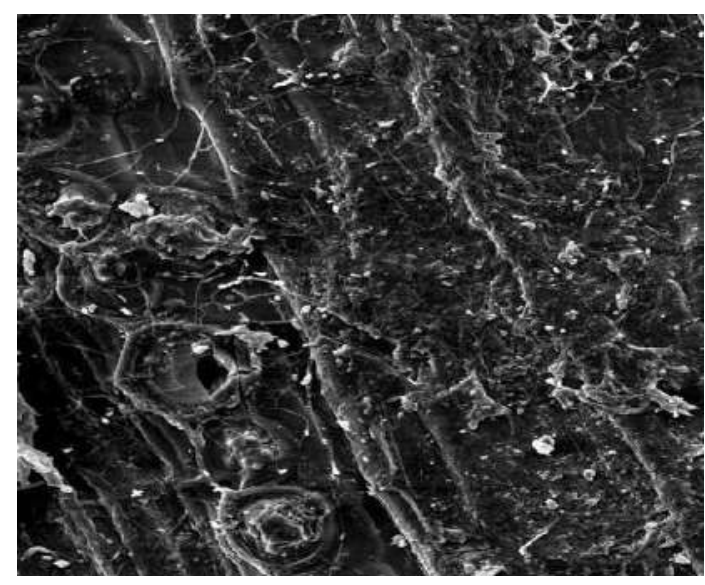

Plate 1: Scanning Electron Micrograph of delignified Grewia optiva fiber

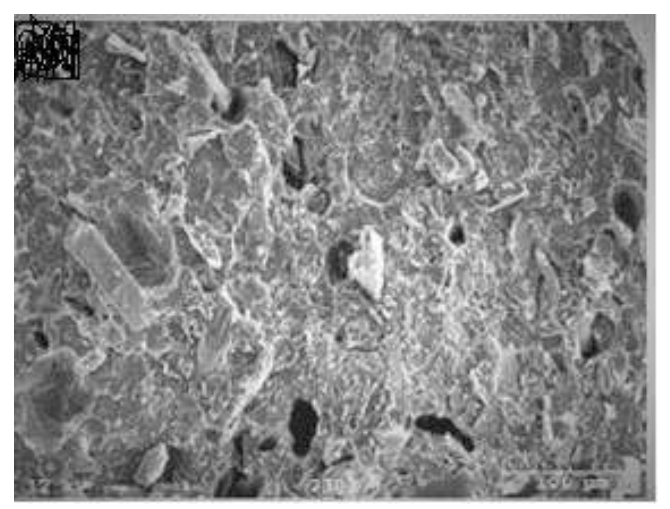

Plate 2: Scanning Electron Micrograph of delignified Grewia optiva fiber -g-PEMA

Thermal Analysis

TGA of delignified fiber, PEMA 
Towards Excellence: An Indexed, Refereed \& Peer Reviewed Journal of Higher Education / Vivek Nandani \& Kinnari Trivedi / Page 350-365

grafted fibersand PEMA were studied as a function of percentage weight loss vs. temperature and 
results are shown in Table-II The initial decomposition temperature (IDT) of the delignified Grewia optiva fiber has been found to be $245^{\circ} \mathrm{C}$, while the final decomposition temperature (FDT) was recorded at $370^{\circ} \mathrm{C}$. The grafted sample exhibits two-stage decomposition behavior, IDT and FDT were found to be 280 and $682^{\circ} \mathrm{C}$, respectively, which were much higher than that of the delignified Grewia optiva fiber. It may be due to the decomposition of the cellulosic material in the first stage and decomposition of poly MMA in second stage. The increase in the IDT of grafted fibers could be attributed to the incorporation of the polymer chain on the surface of fiber. In the case of PEMA the overall degradation involves only single step which commences from $250^{0} \mathrm{C}$, followed by a very slow gradual decrease in weight up to $310^{\circ} \mathrm{C}$. Beyond $310^{\circ} \mathrm{C}$, there is a very fast weight loss up to $540^{0} \mathrm{C}$, involving about $67 \%$ weight loss with a maximum rate of weight loss at

$435^{0} \mathrm{C}$. The overall degradation leaves about $9 \%$ residue.

\section{$\underline{\text { Table-II }}$}

\begin{tabular}{|c|c|c|c|c|c|c|c|}
\hline \multirow[t]{2}{*}{ Sample Name } & \multirow[t]{2}{*}{$\%$ PG } & \multirow[t]{2}{*}{$\operatorname{IDT}\left({ }^{\mathbf{U}_{C}}\right)$} & \multirow[t]{2}{*}{$\operatorname{FDT}\left({ }^{{ }^{0} C}\right)$} & \multicolumn{3}{|c|}{$\begin{array}{l}\text { DT }\left({ }^{0} \mathrm{C}\right) \text { at } \\
\text { every } 20 \% \\
\text { weight loss }\end{array}$} & \multirow[t]{2}{*}{$\begin{array}{l}\text { Residual } \\
\text { left(\%) }\end{array}$} \\
\hline & & & & 20 & 40 & 60 & \\
\hline delignified Grewia optiva & - & 245 & 370 & 280 & 320 & 339 & 17.84 \\
\hline delignified Grewia optiva -g-PEMA & 126.25 & 280 & 682 & 301 & 341 & 401 & 13.39 \\
\hline PEMA & -- & 250 & 540 & 329 & 380 & 425 & 9.89 \\
\hline
\end{tabular}




\section{Reference}

1. Necula, A. M., Olaru, N., Olaru, L., Homocianu, M., and Ioan, S. (2010). J. Appl. Polym. Sci. 115, 1751-1757

2. Ramanaiah, K., Ratnaprasad, A. V., Hema, K., and Reddy, C. (2011a). Int. J. Polym. Anal. Char.

3. Ramanaiah, K. A. V., Prasad, R., Hema, K., and Reddy, C. (2011b). Int. J. Polym. Anal. Char.

4. Kiani, G. R., Sheikhloie, H., and Arsalani, N. (2011). Deselination 269, 266-270

5. Kaith, B. S., and Kalia, S. (2007). Polym. J. 39, 1319-1327

6. E. A. Abdel-Razik, (1996) Carbohyd. Polym.; 31, 23

7. S. H. Samaha, H. E. Nasr and A. Hebeish, (2005) J. Ploym. Res.; 12, 343

8. A. Waly, F. A. Abdel-Mohdy and A. Hebeish, (1998) Polymer and Polymer Composites; 6,161

9. Balbir Singh Kaith, Rajeev Jindal and Jaspreet Kaur Bhatia, (2011) J. Macromol. Sci.; A48, 299

10. Lawrence O. Ekebafe, Joseph E. Imanah, Mariam O. Ekebafe, and Stella O. Ugbesia, (2010) The Pacific Journal of Science and Technology; 11,. 488.

11. L.O. Ekebafe, M.O. Ekebafe, F.A.O. Akpa, G. Erhuanga and B.W. Etiobhio; (2011) Chemical Industry \& Chemical Engineering Quarterly 17, 133

12. A. Srivastava, J. Tripathi, M. M. Mishra and K. Behari, (2006) J. Appl. Polym. Sci.; 106, 1353

13. E. A. Abdel-Razik, (1996) Carbohyd.

Polym.; 31, 23

\section{Vivek Nandani \\ Manager Quality control (Topical Formulation) Zydus Cadila Healthcare \\ Ltd. Ahemdabad \\ \& \\ Kinnari Trivedi \\ Organic Chemistry Department, Institute of Science \& Technology for Advanced Studies \& Research (ISTAR), CVM University, Vallbha Vidyanagar}

